\title{
EL ANTIGUO RETABLO MAYOR DE SAN FELIPE NERI DE CUENCA
}

El arquitecto turolense José Martín de Aldehuela (1719-1802) llevó a cabo en Cuenca, durante el tercer cuarto del siglo XVIII, una labor profesional tan cuantiosa que cambiaría por completo la faz monumental de la ciudad. La trascendencia de dicho quehacer fue pregonada por Chueca Goitia en un memorable artículo ${ }^{1}$, y luego amplificada por Barrio Moya en su tesis doctoral sobre la arquitectura barroca conquense ${ }^{2}$. Por desdicha, los avatares históricos se han cebado cruelmente con este bellísimo patrimonio dieciochesco, que ha perdido prácticamente todo su mobiliario tras la Guerra Civil española. El hallazgo esporádico de material fotográfico anterior a 1936, permite reconstruir el fastuoso empaque originario de algunos de los interiores creados por Aldehuela. Es lo que pretendemos en el presente estudio con la iglesia de San Felipe Neri y su monumental (y perdido) retablo del altar mayor.

El oratorio de San Felipe Neri se fundó el 14 de septiembre de 1738, por los hermanos Alvaro e Isidro Carvajal y Lancáster. Ambos eran canónigos de la catedral de Cuenca, de la que más tarde don Isidro llegaría a ser obispo. Se afirma que José Martín fue llamado para acabar una iglesia que ya se construía ${ }^{3}$ pero, como bien argumenta José Luis Barrio, tanto la planta como la ornamentación son características de la primera manera del turolense, lo que acredita su completa autoría. Referencia cronológica válida para las obras es la del 12 de enero de 1748, cuando los padres de la Congregación solicitan al ayuntamiento la ampliación del solar, para erigir una capilla a su patrona la Virgen de la Luz. La iglesia estaría terminada en $1754^{4}$. Es templo de una nave, cabecera plana y cierre poligonal a los pies. El crucero es muy amplio y cubierto por bóveda vaída, al que se abre la citada capilla, de planta elíptica y techada con cúpula. Destaca en especial la profusa decoración rococó del interior, sin paralelo en nuestro arte ${ }^{5}$.

Durante la Guerra Civil, la iglesia se utilizó como almacén y como establo, y fueron quemadas todas las piezas que componían su mobiliario. Chueca, que la contempló en el otoño de 1943, la describe ennegrecida por el humo y con un penoso aspecto. Afortunadamente, ha sido restaurada entre 1987 y 1992, con un elogiable comportamiento personal del rector del templo ${ }^{6}$, que ha buscado la recreación de la policromía y del ambiente primitivo. La indudable belleza dieciochesca que hoy ofrece a sus visitantes no debe hacer olvidar que representa sólo una parte de la que desplegó en el pasado. Hay que embutir en este espacio vacío, con la imaginación, los tres altares primitivos: el mayor, dedicado a la Santísima Trinidad; el de la Virgen de la Luz, en la capilla elíptica, y el ofrendado al mismo San Felipe Neri, suponemos que en el brazo derecho del crucero (lado de la Epístola). Además, deben agregarse los púlpitos de caprichosas formas, las tribunas y otros elementos artísticos.

La fotografía que adjuntamos con estas páginas debió de ser realizada en la década de los años veinte (fig. 10). Tanto el presbiterio como el altar mayor se encuentran invadidos por motivos florales y colgaduras que acreditan una celebración festiva. En estas fechas, eran los redentoristas quienes ocupaban el antiguo edificio de los filipenses. Se observa cómo el lienzo principal queda semiescondido tras un postizo con la Virgen del Perpetuo Socorro, cuyo culto favorecieron precisamente los redentoristas.

1 Chueca, F.: «José Martín de Aldehuela. Datos para el estudio de un arquitecto del siglo XVIII». Arte Español, XV (1944), pp. 9-28.

2 Barrio, J.L.: Arquitectura barroca en Cuenca. Universidad Complutense de Madrid, 1991.

3 Llaguno, E.: Noticias de los arquitectos y arquitectura en España desde su restauración, IV. Madrid, 1977, p. 297.

${ }^{4}$ Barrio, J.L.: op. cit., pp. 325-332.

5 Los grandes medallones de la bóveda y los arcos triunfales del crucero ofrecen, en opinión de Chueca, las más puras y fantasiosas composiciones en rocalla que se pueden encontrar en España (Chueca, F.: op. cit., p. 14).

6 Agradezco a don Manuel Martínez Moset las facilidades proporcionadas para la realización de este estudio. 


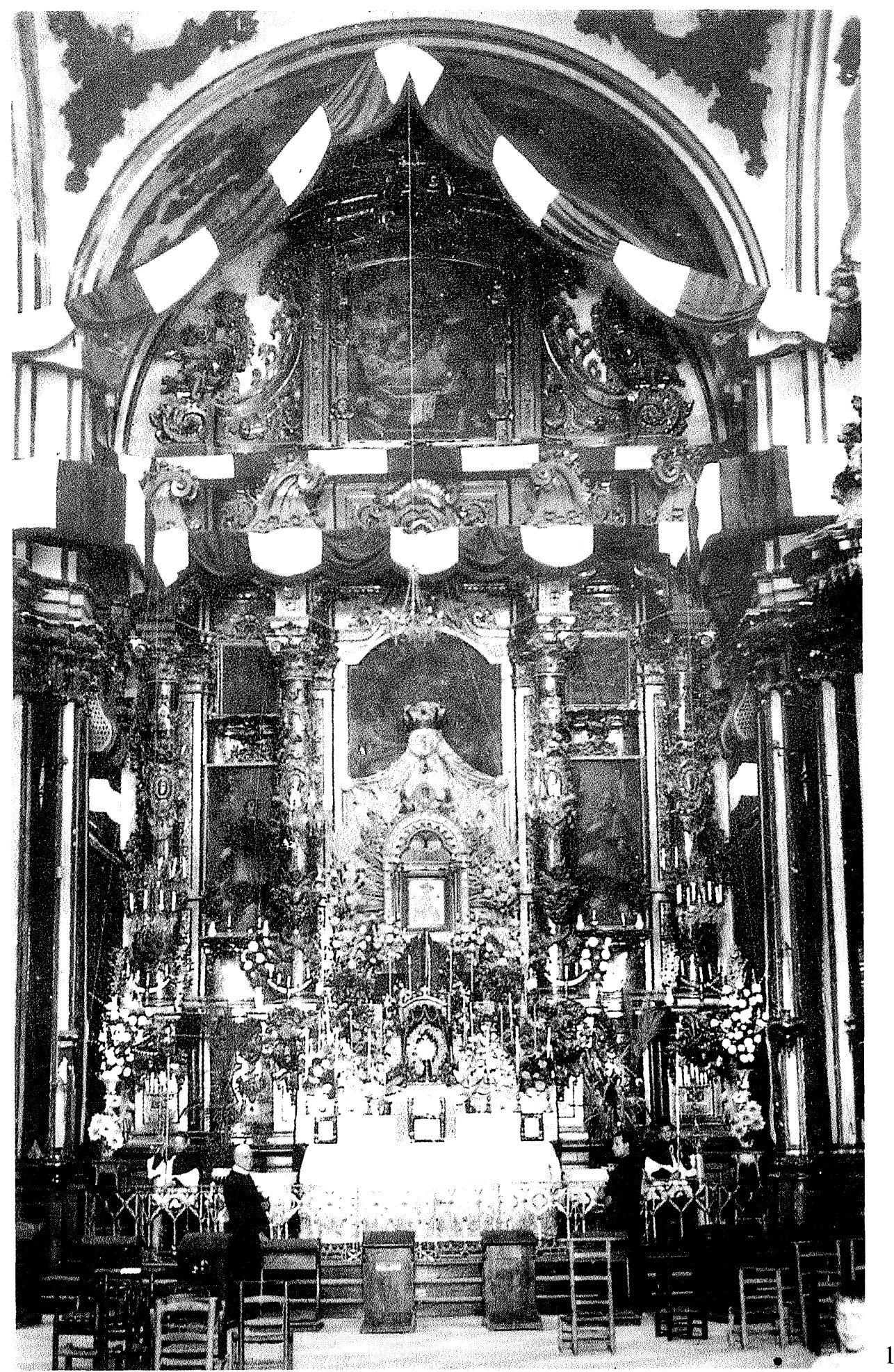

Figura 10. Antiguo Retablo Mayor de la Iglesia de San Felipe Neri de Cuenca (fotografía anterior a 1936). 
Se trataba de un retablo de pincel de grandes dimensiones, que ocupaba por completo el testero plano de la iglesia. Pueden deducirse para él unas medidas de siete metros y medio de ancho por unos catorce de alto. Poseía un cuerpo principal, dividido en tres calles por cuatro columnas de orden compuesto, y coronamiento. Antonio Ponz, hacia 1774, recoge los asuntos pictóricos de la calle central y los nombres de los maestros que los ejecutaron: «El espacio principal...lo ocupa un cuadro grande con la Santísima Trinidad; lo hizo en Roma don Francisco Preciado...En el último cuerpo del altar hay colocada una Asunción de Nuestra Señora, ejecutada por don Antonio Velázquez» ${ }^{7}$. Con la cautela que puede suponerse, debido a las dificultades existentes, hemos calculado para la Trinidad un tamaño de 3,60 x 1,75 m, y 2,25 x 1,70 m para la Asunción. Las calles laterales se desdoblan en dos temas de pincel diferentes. Los superiores, de formato cuadrangular, se muestran tan oscurecidos que nada puede concluirse de su contenido. Los inferiores, oblongos, representan a dos santos de cuerpo entero. El del lado de la Epístola debe de personificar a San Felipe Neri (aprox. 1,95 x 0,95 m). Las dudas son mayores en la identificación del santo del lado del Evangelio. Con reservas, avanzamos la hipótesis de San Carlos Borromeo (aprox. 1,95 x 0,95 m).

La traza del retablo sería del propio Martín de Aldehuela, y de ahí su perfecta adecuación al ambiente arquitectónico y ornamental del edificio. Compartiendo trascendencia con la iglesia, significa un hito dentro de la retablística conquense. Si lo comparamos con otro notable altar mayor no muy lejano en el tiempo, el de la parroquial de Villanueva de la Jara, pueden advertirse fácilmente las diferencias. Este, con la robustez de sus miembros arquitectónicos y el fuerte claroscuro, se mantiene dentro de la tipología churrigueresca. Por el contrario, el mayor de San Felipe Neri inaugura con toda su pureza la fase plenamente rococó. Aunque las añadiduras de telas y flores no permiten recrear con exactitud la planta, puede advertirse la convexidad que afecta al cuerpo principal. Típicas son la delicadeza y relativa planitud de los elementos. También el diseño ondulante y mixtilíneo del coronamiento, con los aletones espiraliformes. Los soportes columnarios pierden los motivos vegetales omnipresentes en la fase anterior, sustituidos por una decoración adventicia y geometrizada. Las rocallas, los medallones ovalados y las cabezas de serafines se reparten con abundancia. Si en su desnudez actual de moblaje artístico, es todavía riquísima la ornamentación de la cabecera de San Felipe Neri, la presencia de esta monumental escenografía dorada la llevaría al límite de la suntuosidad.

En la literatura local, se registran diversos elogios a las pinturas principales del altar. Mateo López califica como «muy bella» la Trinidad $^{8}$. A mediados del siglo XIX, Muñoz y Soliva eleva a «bellísima» la alabanza ${ }^{9}$. Sólo se advierten algunos detalles de la zona superior de la composición, como parte de la figura de Cristo. La obra se pintó en Roma (según advertencia de Ponz), donde el sevillano Francisco Preciado de la Vega (17131789) pasaría tantos años vinculado con los pensionados españoles de la Academia de San Fernando. De conservarse, habría sido una pieza importante del catálogo de este pintor.

7 Ponz, A.: Viaje de España. (Madrid, 1772-1794). Edic. Aguilar, Madrid, 1947, p. 268.

8 López, M.: Memorias históricas de Cuenca y su Obispado. C.S.I.C. y Ayuntamiento de Cuenca, 1949, p. 332 .

9 Muñoz y Soliva, T.: Noticias de todos los Ilmos. Señores Obispos que han regido la diócesis de Cuenca. Cuenca, 1860, p. 117. 
Algo más se percibe - siempre en términos relativos- de la Asunción del coronamiento. También de gran tamaño, sería otra realización notable, en este caso del madrileño Antonio González Velázquez (1723-1794). Muñoz y Soliva la aprecia como «muy buena» ${ }^{10}$. Aquí se distingue la efigie de la Virgen ascendiendo entre nubes y el sepulcro en la base inferior de la pintura. En mayor medida que la Trinidad, del correcto y excesivamente ortodoxo romanista Francisco Preciado, la barroquizante Asunción se acomoda sin estridencias al espíritu con el que Martín de Aldehuela impregna tanto la mazonería del retablo mayor como la iglesia toda. Discípulo de Corrado Giaquinto, Antonio González Velázquez aprendería en Roma los secretos de la pintura mural, que luego tendría ocasión de explicitar en los numerosos frescos realizados en las iglesias madrileñas (Encarnación, Salesas Reales y otras). El casticismo de su estilo, con los aportes modernizadores asimilados en Italia, cuenta puntualmente con ciertos brotes de carácter rococó. Desde luego, su formación como fresquista y la deuda hacia las tendencias teatrales y decorativas del pleno barroco quedan patentes en esta agitada composición de Cuenca, donde los escorzos que caracterizan al maestro madrileño son bien visibles.

La evolución como tracista de retablos de Martín de Aldehuela correrá pareja con su propia mudanza como arquitecto. Se concede una importancia decisiva, en esta transformación, al conocimiento de la arquitectura de Ventura Rodríguez, que en 1752 proyectó el retablo de la capilla mayor y el Transparente de San Julian de la catedral de Cuenca (construidos entre 1753 y 1760). El mismo Ponz lo subrayó al mencionar los altares catedralicios de Nuestra Señora del Pilar y de la Magdalena, y la producción general del turolense, con solapada recriminación aneja a la etapa rococó de éste ${ }^{11}$. La presión del clasicismo academicista en el medio artístico conquense abortaría las posibilidades de una etapa estilística iniciada con un logro tan espléndido como San Felipe Neri. Por ello, la magnificencia rocalla de esta iglesia permanecerá sin descendencia equiparable, como demuestra la parroquial de San Pedro (1758), donde tal ornamentación queda constreñida en sus límites.

Hasta la mitad de los años sesenta, perdura la decoración rococó en los retablos trazados por Aldehuela, como prueban los añadidos del altar renacentista de la capilla de Santiago y el retablo de la sacristía de la catedral (1764-1765) ${ }^{12}$. Poco después, emergen en su catálogo retablos tan característicos como los de San Antonio (1770), la Magdalena (1770) o Santa María del Alba (1772). La deuda en ellos es absoluta hacia las trazas de Ventura Rodríguez para el altar mayor y el Transparente de la catedral. Con el auxilio de la policromía, se imitan en la humilde madera no sólo las trazas generales de aquellas obras, sino la propia calidad de los mármoles y jaspes que las componen. Así, en apenas una década, Martín de Aldehuela alcanza los antípodas estéticos del espléndido retablo mayor de San Felipe Neri.

Pedro Miguel Ibáñez Martínez Universidad de Castilla-La Mancha

10 Muñoz y Soliva, T.: Ibíd.

11 Ponz, A.: op. cit., pp. 256-257.

12 Sobre estos retablos, véase Bermejo, J.: La catedral de Cuenca. Cuenca, 1977, pp. 56, 77, 179, 180, 191, 296 y 297. 